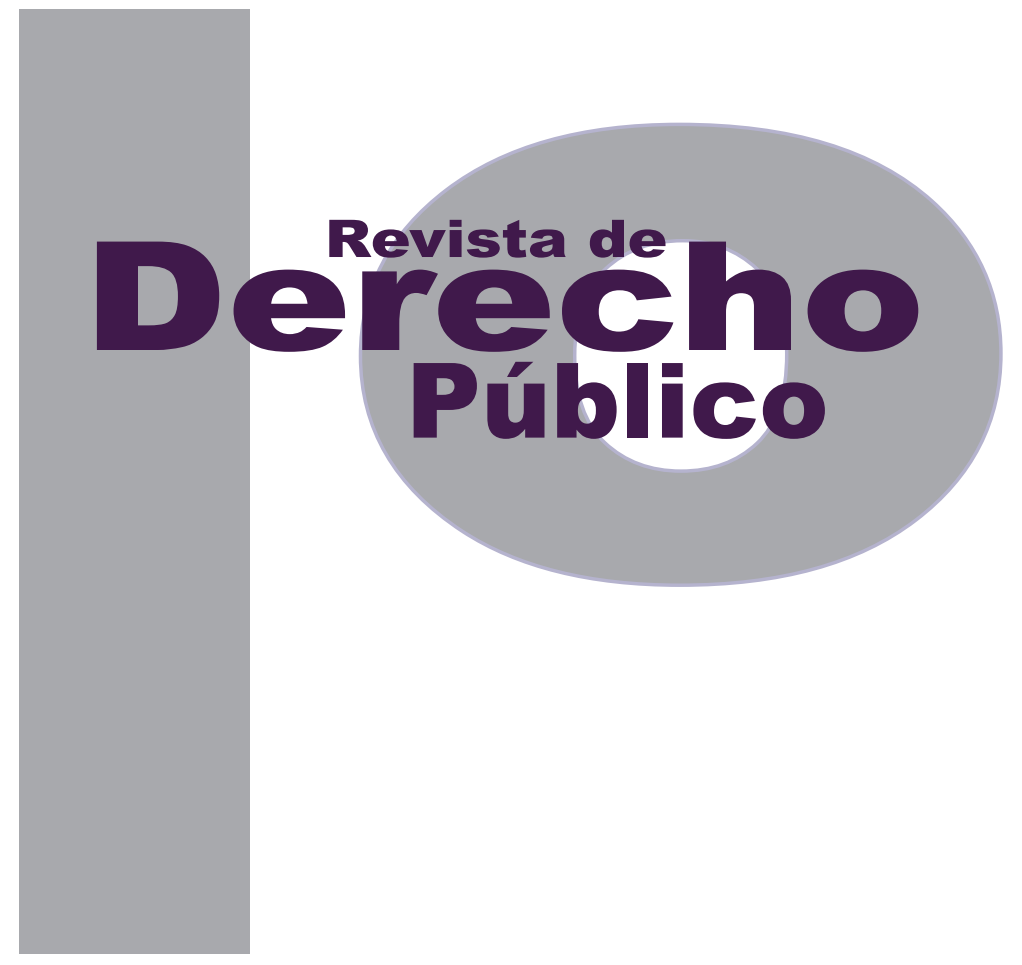

\title{
HIDROCARBUROS: MARCO INSTITUCIONAL Y LEGAL COLOMBIANO
}

\author{
Ángela María Prada Cadavid \\ Artículo corto \\ DOI: http://dx.doi.org/10.15425/redepub.34.2015.04 \\ Universidad de los Andes \\ Facultad de Derecho \\ Revista de Derecho Público N. ${ }^{\circ} 34$ \\ Enero - Junio de 2015. ISSN 1909-7778
}




\title{
Hidrocarburos: marco institucional y legal colombiano
}

\section{Resumen}

Las riquezas del país en recursos naturales, entre ellos los hidrocarburos, han llevado a la tarea y a la necesidad de que el Estado, de manera permanente, despliegue su función administrativa de regulación y control a través de la creación de marcos institucionales y legales respecto a la exploración, explotación, refinación, transporte, almacenamiento, distribución y comercialización de estos en el país. Sin embargo, en el marco institucional colombiano y como producto de la coexistencia de una gran cantidad de organismos de carácter público y subespecializados, existen dificultades que afectan la gestión administrativa y que conllevan que cuando se requiere la ejecución de un procedimiento de esta naturaleza esté mediado por múltiples trámites, una extensa burocracia, dilatación y, consecuentemente, la dificultad en el desarrollo de una prestación de servicio eficiente y eficaz* para todos los actores. En el marco legal el panorama tampoco es alentador, debido a la gama de disposiciones normativas segregadas, dispersas, específicas, que funcionan de manera atomizada y particularizada en diversos temas y que dificultan en la práctica el desarrollo de estas actividades en concordancia con los retos impuestos por el mercado mundial.

En tal perspectiva, este trabajo pretende hacer una reconstrucción teórica de estos dos frentes (el institucional y el normativo), y con base en ella verificar las condiciones de atomización legislativa que lleva a la dispersión en el cumplimiento de la función administrativa, y plantear que es esta la causa quizás más relevante que desvirtúa modelos de prestación de servicios eficientes por parte del Estado y los particulares, afectando con ello el acceso colectivo a los beneficios y el disfrute del bienestar, así como la satisfacción de los intereses sociales que desde ellos se pretende subsanar.

Palabras clave: hidrocarburos, función administrativa, marco legal, marco institucional.

\section{Hydrocarbons: Colombian institutional and legal framework}

\begin{abstract}
The wealth of the country because of natural resources, including oil, has led to the task and the need to permanently deploy its administrative state regulation and control function through the creation of institutional and legal frameworks against the exploration, production, refining, transportation, storage, distribution and marketing them in the country. However, since the Colombian institutional framework in this field, there is a substantial difficulty product creation and coexistence of a large number of specialized agencies public and sub, which directly affects the administration, since the vast institutional dispersion entails that when the implementation of an administrative proceeding is required, it is itself mediated by multiple steps, leading to a large bureaucracy, delaying the implementation of the actions and hindering the development of the provision of efficient and effective service to all actors involved and interested in the subject. In legal terms, the outlook is not encouraging, because there is a wide range of segregated provisions, scattered, concrete and operating atomic and particularized policy on various issues, making it difficult in practice to develop these activities in consistent with the challenges posed by the global market against them.

In this perspective, this paper aims to make a theoretical reconstruction of these two fronts (the institutional and regulatory) to verify the conditions of legislative fragmentation leading to the dispersion in the performance of administrative functions with them, and argue that these are one of the reasons, perhaps the most important, that distort models provide efficient and effective services by the state and individuals, thus affecting access to and enjoyment of social welfare benefits and the satisfaction of social interests from they are intended to cover.
\end{abstract}

Keywords: hydrocarbons, administrative functions, legal framework, institutional framework.

Principios constitucionales rectores de la función administrativa. 


\section{Hidrocarbonetos: marco institucional e legal colombiano}

\section{Resumo}

As riquezas do país em recursos naturais, entre eles os hidrocarbonetos, tem levado à tarefa e à necessidade de que o Estado, de maneira permanente, desdobrem sua função administrativa de regulação e controle através da criação de marcos institucionais e legais respeito à exploração, refinação, transporte, armazenamento, distribuição e comercialização destes no país. Porém, no marco institucional colombiano e como produto da coexistência de uma grande quantidade de organismos de carácter público e subespecializados, existem dificuldades que afetam a gestão administrativa e que implicam que quando se requer a execução de um procedimento desta natureza esteja mediado por inúmeros trâmites, uma extensa burocracia, dilatação e, consequentemente, a dificuldade no desenvolvimento de uma prestação de serviço eficiente e eficaz para todos os atores. No marco legal o panorama tampouco é alentador, devido à gama de disposições normativas segregadas, dispersas, específicas, que funcionam de maneira atomizada e particularizada em diversos temas e que dificultam na prática o desenvolvimento destas atividades em concordância com os desafios impostos pelo mercado mundial.

Em tal perspectiva, este trabalho pretende fazer uma reconstrução teórica destas duas frentes (a institucional e a normativa), e com base nela verificar as condições de atomização legislativa que leva à dispersão no cumprimento da função administrativa, e expor que é esta a causa talvez mais relevante que desvirtua modelos de prestação de serviços eficientes por parte do Estado e dos particulares, afetando com isso o acesso coletivo aos benefícios e o desfrute do bem-estar, assim como a satisfação dos interesses sociais que desde estes se pretende corrigir.

Palavras-chave: hidrocarbonetos, função administrativa, marco legal, marco institucional. 


\title{
Hidrocarburos: marco institucional y legal colombiano*
}

\author{
Ángela María Prada Cadavid**
}

\section{SUMARIO}

Introducción - I. ALGUNAS DISCUSIONES PREVIAS SOBRE HIDROCARBUROS EN COLOMBIA - A. Qué son los hidrocarburos - B. Breve historia de la explotación de hidrocarburos en Colombia - C. Función administrativa - II. MARCO INSTITUCIONAL DE HIDROCARBUROS EN COLOMBIA - A. Marco institucional del sector central en materia de hidrocarburos en Colombia - 1. Presidente de la República - 2. Departamento Nacional de Planeación - 3. Consejo Nacional de Política Económica y Social (Conpes) - 4. Ministerios - 4.1. Ministerio de Minas y Energía - 5. Comisión de Regulación de Energía y Gas (CREG) - B. Marco institucional del sector descentralizado en materia de hidrocarburos en Colombia - 1. Unidades adscritas - 2. Entidades vinculadas - III. MARCO LEGAL SOBRE HIDROCARBUROS EN COLOMBIA - A. Constitución Política - B. Código de Petróleos - C. Decretos reglamentarios - IV. CONCLUSIONES - Referencias.

* Cómo citar este artículo: Prada Cadavid, A. M. (Junio, 2015). Hidrocarburos: marco institucional y legal colombiano. Revista de Derecho Público, 34. Universidad de los Andes (Colombia).

Artículo de reflexión producto del trabajo, Hidrocarburos: marco institucional y legal colombiano, presentado para optar por el título de Especialista en Derecho Administrativo, Universidad Santo Tomás, Medellín, 2014.

** Filósofa, Universidad de Antioquia. Abogada, Universidad Santo Tomás, Medellín. Doctoranda en Ciencia Política, Universidad Nacional de Rosario, Argentina. Vinculada a la Institución Universitaria Salazar y Herrera como jefe del Centro de Humanidades, docente en el Programa de Derecho e investigadora Grupo fEs. Docente de la Facultad de Educación de la Universidad Santo Tomás Abierta y a Distancia, Centro de Atención Universitaria, Medellín. 


\section{Introducción}

En las proyecciones para impulsar el progreso del país, la dinamización de los sectores económicos constituye una de las estrategias más importantes dentro de las alternativas propuestas en la planeación nacional. Uno de ellos es el sector minero y energético donde se articula la explotación de hidrocarburos, que a la fecha constituye una de las grandes fuentes de riqueza en Colombia y con la cual se pretende "generar crecimiento sostenible y mayor equidad social, regional e intergeneracional" (Departamento Nacional de Planeación [DNP], 2010).

Sin embargo, las condiciones regulatorias desde las cuales se busca cumplir en parte esta perspectiva de desarrollo presentan grandes dificultades por causa de la atomización administrativa y legislativa reinante. Las funciones administrativas a cargo de cada una de las instituciones públicas responsables de la administración, vigilancia y control sobre el tema se encuentran dispersas y en ocasiones son difusas, y las normas que rigen y fundamentan dicha función se encuentran dispersas en una gran cantidad de disposiciones legislativas, lo que dificulta su conocimiento y articulación.

Debido a esto, a través de un proceso de investigación de carácter documental se buscará recoger y recopilar lo relacionado con los hidrocarburos en Colombia, desde una reconstrucción teórica de las funciones administrativas del Estado expresadas en las acciones de regulación y control, el marco institucional en cabeza del Ministerio de Minas y Energía, las agencias, departamentos administrativos y demás entidades públicas.

Todo con el fin de evidenciar las grandes dificultades ya mencionadas y que repercuten en la burocratización de los procesos, lo cual incide directamente en la libertad de empresa, en las posibilidades de un mayor desarrollo nacional a partir de esta actividad económica y en poder avanzar en la búsqueda de alternativas que limiten este problema.

\section{ALGUNAS DISCUSIONES PREVIAS SOBRE HIDROCARBUROS EN COLOMBIA}

Para vislumbrar la función administrativa del Estado y la macroestructura en materia de hidrocarburos en el país, se deberán establecer algunos criterios básicos que permitan entender dicho fenómeno y el escenario en el cual se desarrolla.

Por ello, y como fundamento de los análisis que se presentan en posteriores acápites, a continuación se procederá a establecer qué son los hidrocarburos, para poder comprender de manera básica a qué se hace referencia cuando se habla de dichos compuestos; posteriormente se expondrá un corto recuento sobre los inicios de la explotación de algunos hidrocarburos en Colombia, y se culminará con una descripción de lo que es la función administrativa del Estado y su desarrollo desde las funciones de regulación. 


\section{A. Qué son los hidrocarburos}

Se puede entender los hidrocarburos como compuestos orgánicos formados por átomos de carbono e hidrógeno, que se encuentran en la naturaleza en estado líquido, gaseoso y a veces sólido. Según los enlaces de carbono y de hidrógeno pueden clasificarse en tres tipos: alifáticos -que a su vez se subclasifican en alcanos, alquenos y alquinos-, alicíclicos y aromáticos.

En estado natural, los hidrocarburos más relevantes son el gas natural y el petróleo crudo, de los cuales se desprenden varios subproductos entre los que se encuentran combustibles; petroquímicos; una gran variedad de plásticos como el polietileno, poliestireno y teflón; y la configuración de aditivos, ceras, parafinas, lubricantes, etc., sin embargo su principal uso es la generación de energía mediante combustión. También de los hidrocarburos se pueden extraer compuestos para la producción de hormonas y vitaminas, condimentos, perfumes y tintes orgánicos, entre otros.

En esta medida, la explotación comercial de los hidrocarburos se considera muy importante en las actividades económicas, especialmente el aprovechamiento de los principales combustibles fósiles (petróleo y gas natural) desde los que se estructura el desarrollo de gran parte de las actividades industriales y comerciales.

\section{B. Breve historia de la explotación de hidrocarburos en Colombia}

En materia de hidrocarburos, dos son esenciales en Colombia: el petróleo y el gas. El primero es una de las principales fuentes de riqueza y el que en gran medida ha contribuido con el desarrollo del país.

La explotación de petróleo se remonta hasta momentos anteriores a la conquista de América, pues ya en las etapas precoloniales los indígenas lo utilizaban para recubrir sus embarcaciones, prender sus hornos y con fines medicinales. Posteriormente, en la época de la conquista, Gonzalo Jiménez de Quesada reporta a España la existencia de petróleo en las inmediaciones del valle medio del río Magdalena, como elemento constitutivo de una nueva riqueza para explotar en el país (Asociación Colombiana de Ingenieros de Petróleos y Asociación Latinoamericana de la Industria del petróleo [ACIPET-ALIP], s.f.).

A finales del siglo XIX se perfora cerca de Barranquilla el primer pozo petrolero, denominado Tubará, que logró producir hasta cincuenta barriles por día y conllevó la construcción de la primera refinería, la Cartagena Oil Refining Co., que tenía una capacidad de 400 barriles diarios (ACIPET-ALIP, S.f.). Estos dos hechos marcaron el inicio de la industria petrolera en Colombia.

La explotación de gas natural se presenta con posterioridad a la del petróleo, por cuanto en principio se consideraba un subproducto de la explotación de crudo, y era quemado en las teas ${ }^{1}$ de los campos petroleros. En 1961 se empieza a reconocer como un hidrocarburo independiente, que tiene sus propios usos, y se prohíbe su quema mediante la Ley 10 de 1961. Luego, en

1 Un tipo de antorcha. 
1973, en la costa Atlántica se inicia la construcción del primer gasoducto para atender las necesidades del sector industrial de esa zona del país (Guerrero Suárez y Llano Camacho, 2003).

Durante este tiempo el Estado colombiano tuvo el monopolio no solo en cuanto al desarrollo de proyectos de exploración y explotación de los hidrocarburos, sino la función de regulación y control. La administración, aprovechamiento y generación de recursos se llevaba a cabo a través de Ecopetrol, entidad creada como empresa industrial y comercial del Estado. En el año de 1991, con la implementación del nuevo texto constitucional, se abre la posibilidad a la libertad de empresa, y con ello a la libre competencia, a nuevas dinámicas económicas que incidieron en la conversión de Ecopetrol en una sociedad pública por acciones, en la que hoy se permite que los particulares puedan concurrir para el aprovechamiento de dichos recursos, conservando el Estado las funciones de regular y controlar las operaciones. La administración del recurso petrolero está actualmente a cargo de la Agencia Nacional de Hidrocarburos (ANH).

\section{Función administrativa}

La función administrativa surge del criterio de separación de poderes y funciones propuesta por Montesquieu en el siglo XVIII, según el cual cada uno de los poderes públicos se encargaría de ejercer unas acciones concretas y particulares en relación con la misión específica para la que fueron constituidos. En esta medida, el órgano ejecutivo es el encargado de administrar los recursos necesarios para cumplir los fines y propósitos del Estado, sin embargo, en la actualidad, no se puede desconocer que desde la función pública que ejercen el poder judicial y el legislativo, también en ocasiones asumen dicha función.

En relación con lo anteriormente planteado, esta se define como "la función realizada por el conjunto de órganos regidos por relaciones de dependencia que se revelan en el derecho a dar instrucciones del órgano superior y en el deber de obedecerlas del órgano inferior" (Gordillo, 1998). Se caracteriza por ser permanente, por encontrarse en cabeza del Estado, por buscar la satisfacción de las necesidades generales de todos los habitantes en el cumplimiento de los fines esenciales del Estado, por encontrarse regulada y limitada por el ordenamiento jurídico propio de país (Ley 489 de 1998), por ejecutarse a través de actos concretos y por implicar facultades expresas y exclusivas para quien lo ejerce.

Al encontrarse en cabeza del Estado, el poder público encargado de ejercerla es el ejecutivo, representado por el presidente como suprema autoridad administrativa, los ministros del despacho y los directores de departamentos administrativos, quienes en conjunto representan el Gobierno nacional; también hacen parte de este las gobernaciones, las alcaldías, las superintendencias, los establecimientos públicos y las empresas industriales o comerciales del Estado (Constitución Política, 1991). Como se mencionó anteriormente, la función administrativa también puede ser ejercida por los otros órganos del poder público y en algunos casos por 
los particulares, como ocurre en la prestación de servicios públicos, aunque la titularidad continúa en poder del Estado.

Entre las facultades que se otorgan a quien ejerce el poder ejecutivo están, la de estructurar el marco institucional acorde con la manera como se llevará a cabo la gestión administrativa en relación con la distribución y ejercicio de las funciones a cumplir; la regulatoria, relacionada con la inspección, vigilancia y control a cargo de las autoridades administrativas y con la facultad jurídica de imponer obligaciones o regular conductas con el fin de realizar el interés general; por último, la atribución sancionatoria, esto es el poder imponer castigos ante el incumplimiento de lo dispuesto, con la intención de llevar a cabo los fines esenciales del Estado. Si bien es cierto existen otras potestades otorgadas en relación con el ejercicio de la función pública, se hace mención de estas tres para relacionarlas a continuación con la materia específica de este estudio.

\section{MARCO INSTITUCIONAL DE HIDROCARBUROS EN COLOMBIA}

Las riquezas del país en razón de los recursos naturales, entre los que se encuentran de manera preponderante los hidrocarburos, han mostrado la necesidad de estructurar y establecer un modelo institucional encargado de definir funciones en relación con su explotación, producción, transporte, refinación y comercialización, pero además ha exigido una tarea permanente de regulación y control que ha conllevado que el Estado mismo se estructure en una serie de instituciones especializadas encargadas de vigilar, reglamentar, condicionar, intervenir e inspeccionar los desarrollos y proyectos en esta materia, en cumplimiento de los marcos legislativos y de los fines esenciales del Estado.

En el marco institucional de hidrocarburos, los particulares y el Estado comparten funciones en relación con la explotación, producción, transporte, refinación y comercialización, situación que se ha venido fortaleciendo cada día más ante la necesidad de potenciar el desarrollo del país, generar mejores condiciones de efectividad y eficiencia, ser más competitivos en el mercado, desarrollar la libertad de empresa y fortalecer los modelos económicos liberales que sustentan la economía en Colombia. Sin embargo, dicha actividad es regulada y sometida a previa autorización, por cuanto la titularidad del suelo y del subsuelo está en cabeza del Estado, mientras este permite que los particulares desarrollen algunas de estas funciones pero conserva el control, la inspección y la vigilancia sobre ellas.

Este trabajo se centrará en la institucionalidad estatal, concretamente en los organismos de orden público nacional del sector de hidrocarburos, atendiendo a la dinámica de la distribución de la función pública enunciada en la Ley 489 de 1998 y la legislación especializada en la materia, que determinan de manera particular y concreta las entidades adscritas a dicha actividad. Sin embargo, cabe advertir que dichas disposiciones han contado con una dificultad sustancial, y es que en materia de hidrocarbu- 
ros hay múltiples opciones frente al aprovechamiento de los recursos y estas, en su mayoría, tienen una relación directa con la prestación de servicios públicos, llevando a la necesidad de crear una gran cantidad de instituciones con muchas funciones, a la generación de entidades subespecializadas y a la burocratización de procesos, lo que finalmente ha dificultado cumplir las funciones en óptimas condiciones.

\section{A. Marco institucional del sector central en materia de hidrocarburos en Colombia}

El sector central comprende aquellas entidades de la rama ejecutiva del poder público determinadas en el artículo 38 de la Ley 489 de 1998. En relación con los hidrocarburos incluye los organismos y entidades en los que reposa el ejercicio exclusivo de las potestades y atribuciones determinadas de manera directa e inmediata en dicho campo, y en las condiciones que han sido definidas en la ley, a saber: el presidente de la República, el Departamento Nacional de Planeación (DNP), el Consejo Nacional de Política Económica y Social (CONPES) y los ministerios, órganos que serán presentados a continuación.

\section{Presidente de la República}

Según lo establece la Constitución Política colombiana, será el presidente de la República la máxima autoridad administrativa, por lo que estará encargado de distribuir los negocios y funciones en los organismos administrativos correspondientes y de ejercer la inspección y vigilancia en los términos que determine la ley.
Estas funciones se declaran de manera general, y aplican en particular y de manera concreta en materia de hidrocarburos.

Además, acorde con el artículo 56 de la Ley 489 de 1998, deberá ejercer la suprema dirección, la coordinación y control de la actividad de los organismos y entidades administrativos, entre los que se encuentran aquellos con funciones en materia de hidrocarburos.

Para concluir, y de acuerdo con la función legislativa otorgada por el numeral 10 del artículo 189 de la Constitución Nacional, podrá ordenar, planear, determinar, condicionar y regular las políticas sobre el sector.

\section{Departamento Nacional de Planeación}

Como entidad encargada de liderar y coordinar la agenda de desarrollo del país, es responsable de

la coordinación y diseño de políticas públicas y del presupuesto de los recursos de inversión, la articulación entre la planeación de las entidades del gobierno nacional y los demás niveles de gobierno; la preparación, el seguimiento de la ejecución y la evaluación de resultados de las políticas, planes, programas y proyectos del sector público, así como realizar en forma permanente el seguimiento de la economía nacional e internacional y proponer los estudios, planes, programas, y proyectos para avanzar en el desarrollo económico, social, institucional y ambiental, y promover la convergencia regional del país (art. 1, D. 1832/2012). 
Esta función surge de las facultades otorgadas en 1936 al Estado colombiano para "racionalizar la producción, distribución y consumo de riquezas" (DNP, 2013). En cumplimiento de lo anterior le corresponde generar planes y estrategias que permitan la consolidación y cumplimiento de los objetivos, lo que llevó a la reestructuración institucional que dio paso a la creación de organismos asesores como los consejos nacionales de economía y de política económica y social.

Su antecesor fue el Departamento Administrativo de Planeación y Servicios Técnicos, creado mediante la Ley 19 de 1958, que fue modificado en 1968 y estructurado como el Departamento Nacional de Planeación.

En relación con los hidrocarburos, en concordancia con el Decreto 1832 de 2012, Ias principales funciones que ejecuta son:

1. Coordinar la formulación del Plan Nacional de Desarrollo para su evaluación por parte del Consejo Nacional de Planeación, el Consejo Nacional de Política Económica y Social -CoNPES- así como su posterior presentación al Congreso de la República.

2. Desarrollar los lineamientos de planeación impartidos por el Presidente de la República y coordinar el trabajo de formulación, ejecución, seguimiento y evaluación de resultados del Plan Nacional de Desarrollo y de otras políticas del Gobierno Nacional con los Ministerios, Departamentos Administrativos y entidades territoriales.
3. Coordinar y apoyar la planeación de corto, mediano y largo plazo de los sectores, que orienten la definición de políticas públicas y la priorización de los recursos de inversión, entre otros los provenientes del Presupuesto General de la Nación y el Sistema General de Regalías.

4. Asegurar una adecuada programación del presupuesto de las diferentes fuentes de recursos de inversión con base en las prioridades del gobierno y objetivos de desarrollo del país.

5. Promover, coordinar y apoyar técnicamente el desarrollo de esquemas de asociación entre el sector privado y público en temas y proyectos de interés del Gobierno Nacional.

6. Desarrollar las actividades necesarias para la correcta implementación del Sistema General de Regalías y ejercer las funciones de Secretaría Técnica de la Comisión Rectora.

7. Administrar el sistema de monitoreo, seguimiento, control y evaluación del Sistema General de Regalías.

8. Apoyar a las entidades territoriales, cuando estas lo soliciten, en la priorización y formulación de los proyectos financiables con recursos del Sistema General de Regalías y su incorporación en el proyecto de Ley Bienal de Presupuesto del Sistema General de Regalías.

9. Ejercer las funciones asignadas al Departamento Nacional de Planeación como Secre- 
taría Técnica del Consejo Nacional de Política Económica y Social -cONPES-.

10. Diseñar la política para la prestación de servicios públicos domiciliarios, participar a través de las Comisiones de Regulación y desarrollar estrategias de control y vigilancia para la adecuada y suficiente prestación de estos servicios.

\section{Consejo Nacional de Política Económica y Social (Conpes)}

La Ley 19 de 1958 creó el Consejo Nacional de Política Económica y Planeación, y determinó que era el órgano encargado de estudiar, proponer, coordinar, vigilar e intervenir las políticas económicas del Estado. Posteriormente, en 1968, se modificó su estructura y se creó el Consejo Nacional de Política Económica y Social (CONPES), que desde ese momento es la máxima autoridad nacional de planeación, así como organismo asesor del gobierno en aquellos aspectos relacionados con el desarrollo económico y social del país, y con el estudio y aprobación de los documentos que contienen el desarrollo de políticas generales presentadas en sesión.

El CONPES, según lo establece el Decreto 2148 de 2009 , en sus sesiones será presidido por el presidente de la República, como director general, y en calidad de miembros permanentes con derecho a voz y voto asistirán: el vicepresidente de la República, todos los ministros, el director del Departamento Administrativo de la Presidencia de la República, el director del Departamento Nacional de Planeación, y el director del Depar- tamento Administrativo de Ciencia, Tecnología e Innovación (COLCIENCIAS). El subdirector general del Departamento Nacional de Planeación será el secretario de los Consejos.

Dentro de las funciones del DNP relacionadas con el CONPES y que operan de manera concreta en el sector de hidrocarburos, según lo establece el Decreto 3517 de 2009 en su artículo 4, se encuentran las siguientes:

1. Presentar, para su estudio y aprobación, la programación macroeconómica anual.

2. Someter a su consideración el Plan Nacional de Desarrollo, en los términos señalados en la Ley orgánica del Plan.

3. Presentar, para su aprobación, las políticas, estrategias, planes, programas y proyectos del Gobierno Nacional.

4. Presentar, para su análisis, estudios sobre la ejecución del Plan Nacional de Desarrollo y sobre las políticas, estrategias, programas y proyectos del Gobierno Nacional.

5. Someter, para su estudio y aprobación, las bases y criterios de la inversión pública.

6. Presentar, para su estudio y aprobación, el monto y distribución de las utilidades y los superávit de las entidades descentralizadas.

\section{Ministerios}

En materia de hidrocarburos, las funciones principales se encuentran en cabeza del Ministerio 
de Minas y Energía, sin embargo, también intervienen el Ministerio de Hacienda y Crédito Público, el Ministerio de Medio Ambiente y Desarrollo Sostenible y el Ministerio de Transporte.

El Ministerio de Hacienda y Crédito Público, a través de la definición, formulación y ejecución de la política económica del país, así como los planes, programas y proyectos relacionados con esta temática; además es el encargado de determinar las estrategias en materia fiscal, tributaria, aduanera, de crédito público y presupuestal sin perjuicio de las funciones específicas del Banco de la República y de las entidades adscritas que poseen funciones concretas en materia de hidrocarburos.

El Ministerio de Medio Ambiente y Desarrollo Sostenible, al definir los parámetros y aprobar las licencias ambientales necesarias en las etapas de exploración, producción, construcción y operación de oleoductos, poliductos, gasoductos, refinerías, centros de almacenamiento, estaciones de servicio, etc.

El Ministerio de Transporte, al ser el organismo encargado de formular y regular las políticas, planes, acciones y proyectos en materia de tránsito, transporte e infraestructura vial del país, necesarias para el desarrollo de este sector.

\subsection{Ministerio de Minas y Energía}

En principio fue el Ministerio de la Economía Nacional quien concentraba las funciones relacionadas con minas y energías, pero a raíz de las dificultades económicas presentadas en el país con ocasión de la Segunda Guerra Mundial y el aprovechamiento de los recursos naturales y el desarrollo de otras fuentes de producción que esta demandaba, mediante Decreto 968 del 18 de mayo de 1940 se creó el Ministerio de Minas y Petróleos como mecanismo de contingencia.

En la reforma administrativa de 1968 se le otorgan a este Ministerio facultades exclusivas en relación con fuentes de energía primarias como lo son el petróleo, el gas natural, el carbón y los minerales radioactivos. Posteriormente, mediante la Ley 2 de 1973 se reestructura el sector de minas y petróleos y se le confieren nuevas facultades con el fin de que pueda ejercer una función eficiente y eficaz en el desarrollo de los recursos naturales no renovables, en especial con los hidrocarburos destinados al abastecimiento energético del país.

En 1974, a través del Decreto 636 se reorganiza el sector minero energético; el Ministerio de Minas y Petróleos pasa a denominarse Ministerio de Minas y Energía con la función principal de formular y adoptar las políticas, planes generales, programas y proyectos del sector, además de fijar los criterios para el planteamiento de la transmisión y distribución de conformidad con la ley.

De manera particular en el sector de hidrocarburos, y de acuerdo con el artículo 2 del Decreto 0381 del 16 de febrero de 2012, tiene como principales funciones:

1. Articular la formulación, adopción e implementación de la política pública del sector administrativo de minas y energía. 
2. Formular, adoptar, dirigir y coordinar la política nacional en materia de exploración, explotación, transporte, refinación, procesamiento, beneficio, transformación y distribución de minerales, hidrocarburos y biocombustibles.

3. Formular, adoptar, dirigir y coordinar la política sobre las actividades relacionadas con el aprovechamiento integral de los recursos naturales no renovables y de la totalidad de las fuentes energéticas del país.

4. Formular políticas orientadas a que las actividades que desarrollen las empresas del sector minero-energético garanticen el desarrollo sostenible de los recursos naturales no renovables.

5. Adoptar los planes de desarrollo del sector minero-energético del país en concordancia con los planes nacionales de desarrollo y con la política del Gobierno Nacional.

6. Expedir los reglamentos del sector para la exploración, explotación, transporte, refinación, distribución, procesamiento, beneficio, comercialización y exportación de recursos naturales no renovables y biocombustibles.

7. Expedir los reglamentos técnicos sobre producción, transporte, distribución y comercialización de energía eléctrica y gas combustible, sus usos y aplicaciones.

8. Expedir la regulación para el transporte de crudos por oleoductos.

9. Adoptar los planes de expansión de la cobertura y abastecimiento de gas combustible.
10. Fiscalizar la exploración y explotación de los yacimientos, directamente o por la entidad a quien delegue.

11. Realizar las actividades relacionadas con el conocimiento y la cartografía del subsuelo directamente o por la entidad a quien delegue.

12. Definir precios y tarifas de la gasolina, diesel (АСРM), biocombustibles y mezclas de los anteriores.

13. Revisar y adoptar el Plan de Expansión de la Red de Poliductos y elaborar y adoptar el Plan de Continuidad, en los cuales se definirán los objetivos, principios, criterios y estrategias necesarias para asegurar la disponibilidad y suministro de los combustibles líquidos derivados, biocombustibles y otros en el mercado nacional, en forma regular y continua.

14. Establecer los criterios que orientarán la remuneración de los proyectos destinados a asegurar la confiabilidad, disponibilidad, continuidad y garantía del suministro de los combustibles líquidos, biocombustibles y otros.

15. Identificar el monto de los subsidios que podrá dar la Nación para los servicios públicos de energía eléctrica y gas combustible, establecer los criterios de asignación de los mismos y solicitar la inclusión de partidas para el efecto en el Presupuesto General de la Nación. 


\section{Comisión de Regulación de Energía y} Gas (CREG)

En 1994, la Ley 142 dio vida a las comisiones de regulación, cuya función, según el artículo 73 consiste en

regular los monopolios en la prestación de los servicios públicos, cuando la competencia no sea, de hecho, posible; y, en los demás casos, la de promover la competencia entre quienes presten servicios públicos, para que las operaciones de los monopolistas o de los competidores sean económicamente eficientes, no impliquen abuso de la posición dominante, y produzcan servicios de calidad.

En particular, la CREG es una entidad técnica que busca con su intervención que los servicios de energía eléctrica, gas natural y gas licuado de petróleo (GLP) se presten a un mayor número de personas al menor costo posible, garantizando una adecuada remuneración para las entidades prestadoras que permitan calidad, cobertura y expansión.

\section{B. Marco institucional del sector descentralizado en materia de hidrocarburos en Colombia}

Cuando se habla del sector descentralizado se hace referencia al traslado de competencias que hace el orden central, a través de las potestades otorgadas por el ordenamiento jurídico, a personas jurídicas públicas sobre las cuales se ejerce función de tutela.
Establece el artículo 68 de la Ley 489 de 1998: son entidades descentralizadas del orden nacional, los establecimientos públicos, las empresas industriales y comerciales del Estado, las sociedades públicas y las sociedades de economía mixta, las superintendencias y las unidades administrativas especiales con personería jurídica, las empresas sociales del Estado, las empresas oficiales de servicios públicos y las demás entidades creadas por la ley o con su autorización, cuyo objeto principal sea el ejercicio de funciones administrativas, la prestación de servicios públicos o la realización de actividades industriales o comerciales con personería jurídica, autonomía administrativa y patrimonio propio [cursivas añadidas]

pero además, determina dicha ley que aunque gozan de autonomía administrativa ello no las exime de estar sujetas al control político y a la dirección del órgano al cual están anexas.

En este sentido, la misma ley distingue entre aquellas que se encuentran adscritas y las determinadas como vinculadas. Las primeras cumplen principalmente funciones o servicios especialmente administrativos y las segundas se ocupan esencialmente de la prestación de servicios comerciales, industriales, financieros y de naturaleza civil, compitiendo con los particulares en el mercado de los sectores específicos en los que se desenvuelven.

Las entidades adscritas deben ceñirse estrictamente al régimen de expedición de actos, de celebración de contratos y al régimen de personal que rige para la administración central del Estado y, consecuente con ello, son titulares de 
las potestades administrativas unilaterales o prerrogativas del poder público. Las vinculadas para el cumplimiento de su objeto están sometidas al mismo régimen de actos y contratos que rige para los particulares, pues su actividad, para el caso de las comerciales, industriales y financieras, está en función del mercado y de la competitividad (Molano López, 2005).

En materia de hidrocarburos se presentan tanto las entidades adscritas como las vinculadas, las cuales apoyan a la administración pública en la realización de las funciones y actividades administrativas, comerciales e industriales necesarias para el cumplimiento de los objetivos del sector, como se verá a continuación.

\section{Unidades adscritas}

En el sector de hidrocarburos las unidades adscritas se encuentran clasificadas en unidades administrativas especiales con personería jurídica, agencias e institutos.

Como unidad administrativa especial se encuentra la Unidad de Planeación Minero Energética (UPME), creada mediante el Decreto 2119 del 29 de diciembre de 1992. Posteriormente, la Ley 143 de 1994 en su artículo 13 estableció que estaría adscrita al Ministerio de Minas y Energía, con patrimonio propio y personería jurídica, y con regímenes especiales en materia de contratación y administración de personal, de salarios y de prestaciones, y con autonomía presupuestal. La UPME tiene la importante labor de apoyar la planeación y formulación de políticas públicas en materia de minas y energías; coor- dinar la información sectorial entre todos los agentes a fin de cumplir los logros y objetivos en la materia; y a partir del Decreto 1258 de 2013 la función de planear en forma integral, indicativa, permanente y coordinada con los agentes del sector el desarrollo y aprovechamiento de los recursos mineros y energéticos, la producción y divulgación de la información requerida para la formulación de políticas y toma de decisiones, así como apoyar al Ministerio de Minas y Energía en el logro de sus objetivos y metas.

La Agencia Nacional de Hidrocarburos (ANH) fue creada mediante el Decreto 1760 del 26 de junio de 2003 como Unidad Administrativa Especial adscrita al Ministerio de Minas y Energía, con personería jurídica, patrimonio propio, autonomía administrativa y financiera, cuya función principal era la administración integral de las reservas de hidrocarburos de propiedad de la nación. En el año 2011, a través del Decreto 4137 se reestructura su naturaleza jurídica y se convierte en Agencia Estatal del sector descentralizado de la rama ejecutiva del orden nacional, con personería jurídica, patrimonio propio y autonomía administrativa, técnica y financiera, adscrita al Ministerio de Minas y Energía, decisión que fue ratificada en el Decreto 714 de 2012, con el fin de que pueda responder a las nuevas condiciones del mercado y a las necesidades y potencialidades del país.

En estas mismas disposiciones se determina que su objetivo es administrar integralmente las reservas y recursos hidrocarburíferos de propiedad de la nación; promover el aprovechamiento óptimo y sostenible de los recursos hidrocarbu- 
ríferos y contribuir a la seguridad energética nacional en beneficio de los colombianos, lo que le implica representar los intereses nacionales en materia de exploración y explotación del subsuelo en relación con estos recursos.

Según lo establece el artículo 3 del Decreto 714 de 2012 tiene como funciones las siguientes:

1. Identificar y evaluar el potencial hidrocarburífero del país.

2. Diseñar, evaluar y promover la inversión en las actividades de exploración y explotación de los recursos hidrocarburíferos, de acuerdo con las mejores prácticas internacionales.

3. Diseñar, promover, negociar, celebrar y administrar los contratos y convenios de exploración y explotación de hidrocarburos de propiedad de la Nación, con excepción de los contratos de asociación que celebró Ecopetrol hasta el 31 de diciembre de 2003, así como hacer el seguimiento al cumplimiento de todas las obligaciones previstas en los mismos.

4. Asignar las áreas para exploración y/o explotación con sujeción a las modalidades y tipos de contratación que la Agencia Nacional de Hidrocarburos, ANH, adopte para tal fin.

5. Apoyar al Ministerio de Minas y Energía en la formulación de la política gubernamental en materia de hidrocarburos, en la elaboración de los planes sectoriales y en el cumplimiento de los respectivos objetivos.
6. Estructurar los estudios e investigaciones en las áreas de geología y geofísica para generar nuevo conocimiento en las cuencas sedimentarias de Colombia con miras a planear y optimizar el aprovechamiento del recurso hidrocarburífero y generar interés exploratorio y de inversión.

7. Convenir, en los contratos de exploración y explotación, los términos y condiciones con sujeción a los cuales las compañías contratistas adelantarán programas en beneficio de las comunidades ubicadas en las áreas de influencia de los correspondientes contratos.

8. Apoyar al Ministerio de Minas y Energía y demás autoridades competentes en los asuntos relacionados con las comunidades, el medio ambiente y la seguridad en las áreas de influencia de los proyectos hidrocarburíferos.

9. Fijar los precios de los hidrocarburos para efectos de la liquidación de regalías.

10. Administrar la participación del Estado, en especie o en dinero, de los volúmenes de hidrocarburos que le correspondan en los contratos y convenios de exploración y explotación, y demás contratos suscritos o que suscriba la Agencia, incluyendo las regalías, en desarrollo de lo cual podrá disponer de dicha participación mediante la celebración de contratos u operaciones de cualquier naturaleza. 
11. Recaudar, liquidar y transferir las regalías y compensaciones monetarias a favor de la Nación por la explotación de hidrocarburos.

12. Efectuar las retenciones de las sumas que por concepto de participaciones y regalías correspondan a las entidades partícipes con destino a los Fondos previstos en la Constitución Política y la ley, y hacer los giros y reintegros en los términos establecidos en ellas.

13. Adelantar las acciones necesarias para el adecuado abastecimiento de la demanda nacional de hidrocarburos.

14. Fijar los volúmenes de producción de petróleo de concesión que los explotadores deben vender para la refinación interna.

15. Fijar el precio al cual se debe vender el petróleo crudo de concesión destinado a la refinación interna para el procesamiento o utilización en el país, y el gas natural que se utilice efectivamente como materia prima en procesos industriales petroquímicos cuando sea del caso.

16. Administrar y disponer de los bienes muebles e inmuebles que pasen al Estado por finalización de contratos y convenios de exploración y explotación, o por reversión de concesiones vigentes, con excepción de los contratos de asociación que celebró Ecopetrol hasta el 31 de diciembre de 2003.

17. Hacer seguimiento al cumplimiento de las normas técnicas relacionadas con la explo- ración y explotación de hidrocarburos dirigidas al aprovechamiento de los recursos de manera racional e integral.

18. Fijar los precios de exportación de petróleo crudo para efectos fiscales y cambiarios.

19. Dirigir y coordinar lo relacionado con las liquidaciones por concepto del canon superficiario correspondiente a los contratos de concesión.

20. Verificar las especificaciones y destinación del material importado en el subsector de hidrocarburos para efectos de aplicar las exenciones previstas en el Código de Petróleos o normas que lo modifiquen o adicionen.

21. Supervisar las especificaciones y destinación del material importado en el subsector de hidrocarburos para efectos de aplicar las exenciones previstas en el Código de Petróleos o normas que lo modifiquen o adicionen.

22. Ejercer las demás actividades relacionadas con la administración de los recursos hidrocarburíferos de propiedad de la Nación.

23. Las demás que le sean asignadas y que le delegue el Ministerio de Minas y Energía, de conformidad con las normas vigentes.

En los institutos adscritos se encuentra el actual Servicio Geológico Colombiano cuyo origen se remonta al año 1916 cuando se creó la Comisión Científica Nacional encargada de realizar 
la cartografía geológica, la exploración de los recursos minerales y el estudio del subsuelo, que en 1940 se denominó Servicio Geológico Nacional y en 1953 recibió el nombre de Instituto Geológico Nacional.

A partir de 1968 asumió las funciones correspondientes al Inventario Minero Nacional y al Laboratorio Químico Nacional y se convirtió en el Instituto Nacional de Investigaciones Geológico Mineras (INGEOMINAS). En 1991, en el marco del Sistema de Ciencia y Tecnología, se reestructura y asume el nombre de Instituto de Investigaciones en Geociencias, Minería y Química conservando la sigla InGEOMINAs. En 1999, por Decreto 1129 del 29 de junio se reestructura y adopta el nombre de Instituto de Investigación e Información Geocientífica, Minero-Ambiental y Nuclear "Ingeominas", con el objetivo de "realizar la investigación y generar la información básica para el conocimiento geocientífico y aprovechamiento del subsuelo del territorio colombiano" (art. 4). Posteriormente la entidad ha sido renovada y modificada constantemente mediante los decretos 2656 y 2657 de 1999, 252, 253 y 3577 de 2004.

Pero es a través del Decreto-Ley 4131 de 2011 que se cambia la naturaleza jurídica del Instituto Colombiano de Geología y Minería "Ingeominas", de establecimiento público a instituto científico y técnico, con personería jurídica, autonomía administrativa, técnica, financiera y patrimonio independiente, adscrito al Ministerio de Minas y Energía, y como tal entra a hacer parte del Sistema Nacional de Ciencia, Tecnología e Innovación (SNCTI).
En cuanto a las funciones relacionadas directamente con el sector de hidrocarburos, establecidas en el Decreto-Ley 4131 de 2011, está la de realizar investigación de recursos del subsuelo para evaluar su potencial.

\section{Entidades vinculadas}

Dentro de las entidades vinculadas relacionadas con el sector de hidrocarburos se encuentra Ecopetrol S. A., una sociedad de economía mixta de carácter comercial, organizada bajo la forma de sociedad anónima, del orden nacional, vinculada al Ministerio de Minas y Energía, de conformidad con lo establecido en la Ley 1118 de 2006.

Tiene como objeto, según lo establecen sus estatutos "el desarrollo, en Colombia o en el exterior, de actividades comerciales o industriales correspondientes o relacionadas con la exploración, explotación, refinación, transporte, almacenamiento, distribución y comercialización de hidrocarburos, sus derivados y productos".

Pero además, en relación con los hidrocarburos, tiene la responsabilidad de:

1. La exploración y explotación de hidrocarburos en áreas o campos petroleros que, antes del $1^{\circ}$ de enero de 2004:

a. se encontraban vinculadas a contratos ya suscritos.

b. estaban siendo operadas directamente por Ecopetrol S. A. 
2. La exploración y explotación de las áreas o campos petroleros que le sean asignadas por la Agencia Nacional de Hidrocarburos -ANH-.

3. La exploración y explotación de hidrocarburos en el exterior, directamente o a través de contratos celebrados con terceros.

4. La refinación, procesamiento y cualquier otro proceso industrial o petroquímico de los hidrocarburos, sus derivados, productos o afines, en instalaciones propias o de terceros, en el territorio nacional y en el exterior.

5. La compra, venta, importación, exportación, procesamiento, almacenamiento, mezcla, distribución, comercialización, industrialización, y/o venta de hidrocarburos, sus derivados, productos y afines, en Colombia y en el exterior.

6. El transporte y almacenamiento de hidrocarburos, sus derivados, productos y afines, a través de sistemas de transporte o almacenamiento propios o de terceros, en el territorio nacional y en el exterior, con excepción del transporte comercial de gas natural en el territorio nacional.

7. La investigación, desarrollo y comercialización de fuentes convencionales y alternas de energía.

8. La producción, mezcla, almacenamiento, transporte y comercialización de componentes oxigenantes y biocombustibles.

9. La operación portuaria.

\section{MARCO LEGAL SOBRE HIDROCARBUROS EN COLOMBIA}

El marco legal en materia de hidrocarburos se estructura alrededor de tres grandes aspectos desde los cuales se lleva a cabo el cumplimiento de las funciones del Estado: el régimen regulatorio, el régimen sancionatorio y el régimen procedimental. Estos, a su vez, se organizan en marcos normativos generales y esenciales que se traducen en una gran cantidad de leyes, decretos, resoluciones, circulares, conceptos y acuerdos que, en relación con el petróleo, sus derivados, el gas natural licuado de petróleo (GPL) y sus derivados, hacen de este un tema muy especializado.

En el régimen regulatorio se reglamentan de manera especial y específica las actividades de exploración, explotación, refinación, transporte, almacenamiento, distribución y comercialización del petróleo, el gas natural, el GLP y cada uno de sus derivados; además, el sustento normativo referente a la estructura de las entidades del sector central y descentralizado que conforman el marco institucional de hidrocarburos en Colombia.

El régimen sancionatorio se constituye a partir de las sanciones establecidas en el régimen regulatorio por incumplimiento de las disposiciones determinadas respecto a cada una de las actividades allí mencionadas.

El régimen procedimental determina las condiciones, procesos y consecuencias que se desprenden de la ejecución de acciones encauza- 
das desde el desarrollo económico en materia de hidrocarburos, y que generan una serie de presupuestos y disposiciones que establecen y determinan la manera como se llevarán a cabo dichas acciones no solo por parte de los particulares sino de la administración. Estas disposiciones presentan, además de la dificultad evidenciada en el marco institucional, la derivada del hecho de regular una materia que cambia de manera permanente en función de las necesidades del mercado, que se caracteriza por ser muy especializada y, por lo mismo, exige legislar de manera particular sobre cada uno de los hidrocarburos, con efectos que conllevan atomización legislativa y en algunos casos el incumplimiento de las funciones del Estado en dicha materia.

Sin embargo, en este trabajo se presenta el marco normativo general en materia de hidrocarburos, advirtiendo que tales disposiciones se descomponen en ordenamientos concretos para cada acción y para cada uno de los componentes orgánicos y sus productos.

\section{A. Constitución Política}

Las disposiciones constitucionales que tienen que ver con los hidrocarburos son:

ARTículo 8. Es obligación del Estado y de las personas proteger las riquezas culturales y naturales de la Nación.

ARTículo 58. (...) Por motivos de utilidad pública o de interés social definidos por el legislador, podrá haber expropiación mediante sentencia judicial e indemnización previa. Esta se fijará consultando los intereses de la comunidad y del afectado. En los casos que determine el legislador, dicha expropiación podrá adelantarse por vía administrativa, sujeta a posterior acción contenciosa administrativa, incluso respecto del precio.

ARTículo 150. Corresponde al Congreso hacer las leyes. Por medio de ellas ejerce las siguientes funciones:

2. Expedir códigos en todos los ramos de la legislación y reformar sus disposiciones.

21. Expedir las leyes de intervención económica, previstas en el artículo 334, las cuales deberán precisar sus fines y alcances y los límites a la libertad económica.

artículo 330. parágrafo. La explotación de los recursos naturales en los territorios indígenas se hará sin desmedro de la integridad cultural, social y económica de las comunidades indígenas. En las decisiones que se adopten respecto de dicha explotación, el Gobierno propiciará la participación de los representantes de las respectivas comunidades.

ARTículo 332. El Estado es propietario del subsuelo y de los recursos naturales no renovables, sin perjuicio de los derechos adquiridos y perfeccionados con arreglo a las leyes preexistentes.

ARTículo 334. La dirección general de la economía estará a cargo del Estado. Este intervendrá, por mandato de la ley, en la explotación de los recursos naturales, en el uso del suelo, en la producción, distribución, utilización y consumo de los bienes, y en los servicios públicos y privados, para racionalizar la economía con el 
fin de conseguir el mejoramiento de la calidad de vida de los habitantes, la distribución equitativa de las oportunidades y los beneficios del desarrollo y la preservación de un ambiente sano.

ARTículo 360. La ley determinará las condiciones para la explotación de los recursos naturales no renovables así como los derechos de las entidades territoriales sobre los mismos.

La explotación de un recurso natural no renovable causará a favor del Estado, una contraprestación económica a título de regalía, sin perjuicio de cualquier otro derecho o compensación que se pacte.

Los departamentos y municipios en cuyo territorio se adelanten explotaciones de recursos naturales no renovables, así como los puertos marítimos y fluviales por donde se transporten dichos recursos o productos derivados de los mismos, tendrán derecho a participar en las regalías y compensaciones.

ARTículo 361. Con los ingresos provenientes de las regalías que no sean asignados a los departamentos y municipios, se creará un Fondo Nacional de Regalías cuyos recursos se destinarán a las entidades territoriales en los términos que señale la ley. Estos fondos se aplicarán a la promoción de la minería, a la preservación del ambiente y a financiar proyectos regionales de inversión definidos como prioritarios en los planes de desarrollo de las respectivas entidades territoriales.

ARTículo 365. Los servicios públicos son inherentes a la finalidad social del Estado. Es deber del Estado asegurar su prestación eficiente a todos los habitantes del territorio nacional.
Los servicios públicos estarán sometidos al régimen jurídico que fije la ley, podrán ser prestados por el Estado, directa o indirectamente, por comunidades organizadas, o por particulares. En todo caso, el Estado mantendrá la regulación, el control y la vigilancia de dichos servicios. Si por razones de soberanía o de interés social, el Estado, mediante ley aprobada por la mayoría de los miembros de una y otra cámara, por iniciativa del Gobierno decide reservarse determinadas actividades estratégicas o servicios públicos, deberá indemnizar previa y plenamente a las personas que en virtud de dicha ley, queden privadas del ejercicio de una actividad lícita.

\section{B. Código de Petróleos}

Establecido en el Decreto 1056 de 1953, este código reglamenta las disposiciones relativas a "las mezclas naturales de hidrocarburos que se encuentran en la tierra, cualquiera que sea el estado físico de aquéllas, y que componen el petróleo crudo, lo acompañan o se derivan de él" (art. 1), regulando además la propiedad, utilidad y forma de explotación de estos y sus derivados.

La regulación general en él contenida se divide en dos tipos de disposiciones: las normativas y las reglamentarias.

Las normativas, que van del artículo 1 al 81, son disposiciones generales relativas a la explotación superficial (arts. 19 al 20); los contratos de exploración y explotación (arts. 21 al 33); la tramitación de propuestas y oposiciones (art. 34); los avisos de perforación y revisión de títulos (arts. 35 al 38); regalías (arts. 39 al 43); im- 
puestos sobre el petróleo de propiedad privada (art. 44); transporte (arts. 45 al 57); refinación y distribución (arts. 58 al 61); exenciones, agotamiento y amortización (arts. 62 al 66); sanciones y caducidad de los contratos (arts. 67 al 68) y las disposiciones finales (arts. 69 al 81).

En las disposiciones reglamentarias, que van del artículo 82 al 231, se encuentran: las disposiciones generales (arts. 82 al 120); lo relativo a la explotación superficial (arts. 121 al 124); los contratos de exploración y explotación (arts. 125 al 172); la tramitación de propuestas y oposiciones (arts. 173 al 180); los avisos de perforación y revisión de títulos (arts. 181 al 182); regalías (arts. 183 al 187); impuestos sobre el petróleo de propiedad privada (art. 188); transportes (arts. 189 al 209); refinación y distribución (arts. 210 al 215); exenciones, agotamiento y amortización (arts. 216 al 225); sanciones y caducidad de los contratos (arts. 226 al 227) y las disposiciones finales (arts. 228 al 231).

Por último, se deben anotar las siguientes modificaciones al Código en estudio: el inciso 3 del artículo 10 fue modificado por el artículo 76 de la Ley 962 de 2005, en la que se dictan disposiciones sobre racionalización de trámites y procedimientos administrativos de los organismos y entidades del Estado y de los particulares que ejercen funciones públicas o prestan servicios públicos; el inciso 1 del artículo 10 fue derogado por el artículo 118 de la Ley 1563 de 2012, por la cual se expide el Estatuto de Arbitraje Nacional e Internacional y se dictan otras disposiciones-; y los artículos 93, 94 y 95 fueron reformados por la Ley 1274 de 2009, por la cual se establece el procedimiento de avalúo para las servidumbres petroleras.

\section{Decretos reglamentarios}

El Decreto 1056 de 1953 ha sido desarrollado por los decretos 1717 de 2008 por el cual se modifica el Decreto 4299 de 2005 y se establecen otras disposiciones; el 1333 de 2007 por el cual se modifica el Decreto 4299 de 2005 y se establecen otras disposiciones; el 2400 de 2006 por el cual se regula la construcción de Interconexiones Internacionales de Gas Natural; el 2165 de 2006 por el cual modifica parcialmente el Decreto 4299 de 2005; el 3563 de 2003 por el cual se modifican los artículos 10 y 11 del Decreto 1503 del 19 de julio de 2002; el 1503 de 2002 por el cual se reglamenta la marcación de los combustibles líquidos derivados del petróleo en los procesos de almacenamiento, manejo, transporte y distribución; el 624 de 1994 por el cual se adopta el Procedimiento de Selección para la Contratación de Gasoductos de Uso Público; el 408 de 1993 por el cual se reglamenta parcialmente el artículo 46 del Decreto-Ley 1056 de 1953; el 625 de 1992 por el cual se reglamenta parcialmente el capítulo VIII del Decreto 1056 de 1953; y el 609 de 1990 por el cual se reglamenta parcialmente el capítulo VII del Decreto-Ley 1056 de 1953 y se derogan unas disposiciones.

\section{CONCLUSIONES}

En el Plan Nacional de Desarrollo 2010-2014 se establece como uno de los elementos que impulsará el progreso del país la dinamización 
de sectores económicos a través de unos ejes trasversales denominados "locomotoras". Una de dichas locomotoras es el sector minero-energético, en nuestro caso la exploración, explotación, refinación, transporte, almacenamiento, distribución y comercialización de hidrocarburos, el cual resulta complejo potenciar y lograr los objetivos esperados, dadas las dificultades en relación con la atomización institucional, administrativa y legal antes comentada.

Si lo que se busca es ser más competitivos en el mercado y potenciar los hidrocarburos como una fuente de riqueza y desarrollo para el país, será necesario que el gobierno nacional articule de manera sistemática el marco institucional minero energético en general, y en particular el de los hidrocarburos.

El marco legal presenta un panorama más complejo, ya que existe una gran cantidad de disposiciones normativas generales y un extenso régimen de regulación para el petróleo y el gas licuado de petróleo y cada uno de sus derivados, incrementado por las exigencias de un mercado cada vez más competitivo y cambiante que exige permanentes actualizaciones y que dificulta el cumplimiento de las funciones del Estado en dicha materia. En este ámbito es clara la necesidad de sistematizar la ley en un ordenamiento jurídico concreto como sería un código único de hidrocarburos.

\section{Referencias}

Asociación Colombiana de Ingenieros de Petróleos en Colombia y Asociación Latinoamerica- na de la Industria del Petróleo. (s.f.). Historia del petróleo en Colombia. Recuperado el 10 de octubre de 2013, de Acipet-Alip: http:// www.alip.org/docs/Historias/breve_historia_petrolera_colombia.pdf.pdf

Constituyente. (1991). Constitución política de Colombia. Bogotá: Legis Editores.

Decreto 1056 de 1953 [Ministerio de Minas y Petróleos]. Por el cual se expide el Código de Petróleos. Abril 20 de 1953.

Decreto 1760 de 2003. [Ministerio de Minas y Energía]. Por el cual se escinde la Empresa Colombiana de Petróleos, Ecopetrol, se modifica su estructura orgánica y se crean la Agencia Nacional de Hidrocarburos y la sociedad Promotora de Energía de Colombia S. A. Junio 26 de 2003.

Decreto 2148 de 2009. [Presidencia de la República]. Por el cual se modifican los decretos 2132 de 1992 y 627 de 1974. Junio 8 de 2009.

Decreto 3517 de 2009. [Departamento Nacional de Planeación]. Por el cual se modifica la estructura del Departamento Nacional de Planeación. Septiembre 15 de 2009.

Decreto 0381 de 2012. [Ministerio de Minas y Energía]. Por el cual se modifica la estructura del Ministerio de Minas y Energía. Febrero 16 de 2012.

Decreto 1832 de 2012. [Departamento Nacional de Planeación]. Por el cual se modifica la 
estructura del Departamento Nacional de Planeación. Agosto 31 de 2012.

Decreto 4137 de 2011. [Ministerio de Minas y Energía]. Por el cual se cambia la naturaleza jurídica de la Agencia Nacional de Hidrocarburos, ANH. DO n. ${ }^{\circ} 48242$.

Decreto 714 de 2012. [Ministerio de Minas y Energía]. Por el cual se establece la estructura de la Agencia Nacional de Hidrocarburos, $\mathrm{ANH}, \mathrm{y}$ se dictan otras disposiciones. Abril 10 de 2012. DO n. ${ }^{\circ} 48397$.

Departamento Nacional de Planeación. (2010). Plan Nacional de Desarrollo 2010-2014. Recuperado el 6 de septiembre de 2013, de DNP: https://www.dnp.gov.co/pnd/pnd20102014.aspx

Departamento Nacional de Planeación. (2013). Acerca de la entidad. Recuperado el 12 de noviembre de 2013 de DNP: https://www.dnp.gov. co/QuiénesSomos/Misiónvisiónorigen.aspx

Gordillo, A. (1998). Tratado de derecho administrativo. (Quinta ed., t. I). Buenos Aires: Fundación de Derecho Administrativo.

Guerrero Suárez, F. y Llano Camacho, F. (2003). Gas natural en Colombia - Gas E.S.P. [Trabajo de grado para la especialización en Administración de Empresas. Universidad ICESI. Bogotá].
Ley 142 de 1994. Por la cual se establece el régimen de los servicios públicos domiciliarios y se dictan otras disposiciones. Julio 11 de 1994. DO n. ${ }^{\circ} 41433$.

Ley 143 de 1994. Por la cual se establece el régimen para la generación, interconexión, transmisión, distribución y comercialización de electricidad en el territorio nacional, se conceden unas autorizaciones y se dictan otras disposiciones en materia energética. Julio 11 de 1994. DO n. ${ }^{\circ} 41434$.

Ley 489 de 1998. Por la cual se dictan normas sobre la organización y funcionamiento de las entidades del orden nacional, se expiden las disposiciones, principios y reglas generales para el ejercicio de las atribuciones previstas en los numerales 15 y 16 del artículo 189 de la Constitución Política y se dictan otras disposiciones. Diciembre 29 de 1998.

Ley 1118 de 2006. Por la cual se modifica la naturaleza jurídica de Ecopetrol S. A. y se dictan otras disposiciones. Diciembre 27 de 2006.

Molano López, M. R. (2005). Transformación de la función administrativa. (Evolución de la administración pública). Bogotá: Pontificia Universidad Javeriana. 